\title{
Morbid Obez Bir Hastada Sağ Staghorn Pelvis Renalis Taşının Retrograd Intrarenal Cerrahi Ille Tedavisi: Bir Olgu Sunumu
}

\author{
Altuğ Tuncel ${ }^{1}$, Çağdaş Şenel ${ }^{1}$, Ali Atan ${ }^{2}$
}

${ }^{1}$ Sağlık Bakanlığı, Ankara Numune Eğitim ve Araştırma Hastanesi, 3. Üroloji Kliniği, Ankara

${ }^{2}$ Gazi Üniversitesi, Tıp Fakültesi, Üroloji Anabilim Dalı, Ankara

Giriş

$\mathrm{O}$ bezite, küresel olarak yaklaşık 300 milyondan fazla kişiyi etkileyen önemli bir sağlık sorunudur. Obez olan kişilerin büyük çoğunluğunda üriner sistem taş hastalığına yatkınlık mevcuttur $(1,2)$. Yapılan çalışmalarda, obezitenin idrarda kalsiyum oksalat, sodyum ve ürik asit atılımını arttırarak üriner sistem taş hastalığı oluşumu için bağımsız bir risk faktörü olduğu bildirilmiştir $(3,4)$. Obez hastalarda $2 \mathrm{~cm}$ 'den büyük böbrek taşlarının cerrahi tedavisinde en sık kullanılan yöntem perkütan nefrolitotomi (PNL)'dir. Bu cerrahi yöntem, obez hastalarda güvenli bir şekilde uygulanmasına rağmen, uzun operasyon süresi, düşük taşsızlık oranı ve yüksek tekrar girişim oranına sahiptir (5). Uluslararası literatürde yer alan bazı çalışmalarda, böbrek taşı nedeni ile PNL yapılan obez hastalarda uzun hastanede kalış süresi ve yüksek komplikasyon oranları bildirilmiştir (6,7). Obez hastalarda, $2 \mathrm{~cm}$ 'nin altındaki böbrek taşlarının tedavisinde vücut dışı şok dalgaları ile taş kırma yöntemi cerrahi olmayan bir tedavi seçeneğidir. Ancak vücut ağırlığı sınırlaması nedeni ile işlem yapılacak olan masanın kullanılamaması, böbrek taşının lokalize edilerek kırılmasındaki zorluk ve ciltböbrek taşı arasındaki mesafenin fazla olması nedeni ile şok dalgasının etkinliğinin azalması gibi nedenler obez hastalarda bu yöntemin başarısını sınırlamaktadır $(5,8)$.

Son yıllarda, bükülebilir üreteroskop kullanılarak yapılan retrograd intrarenal cerrahi (RİRC)'nin klinik uygulamaya girmesi ile birlikte böbrek taşlarının cerrahi tedavisinde yüksek başarı oranları bildirilmiştir (9). RİRC, vücut dışı çok dalgası ile taş kırma yöntemine göre yüksek taşsızlık oranı, PNL'ye göre ise daha düşük komplikasyon oranlarına sahiptir $(10,11)$. Ayrıca bu yöntem, obez hastalardaki böbrek taş1nın cerrahi tedavisinde başarı ile uygulanmaktadır (12-14).

$\mathrm{Bu}$ olgu sunumunda, sağ böbrek pelvis renalis'te $3.2 \mathrm{~cm}$ çapında staghorn taş saptanan morbid obez bir erkek hastanın böbrek taşının cerrahi tedavisinde RİRC deneyimimiz uluslararası literatür bilgileri eşliğinde okuyucu ile paylaşılacaktır.

\section{Olgu sunumu}

Altmış yaşında erkek hasta kolik tarzında tekrarlayan sağ yan ağrısı nedeni ile polikliniğimize başvurdu. Hasta tıbbi öyküsünde, yaklaşık olarak 10 yıldır aralıklar ile kolik tarzında sağ yan ağrısı şikayeti olduğunu ancak herhangi bir sağlık merkezine başvurmadığını belirtti. Hastanın özgeçmişinden,
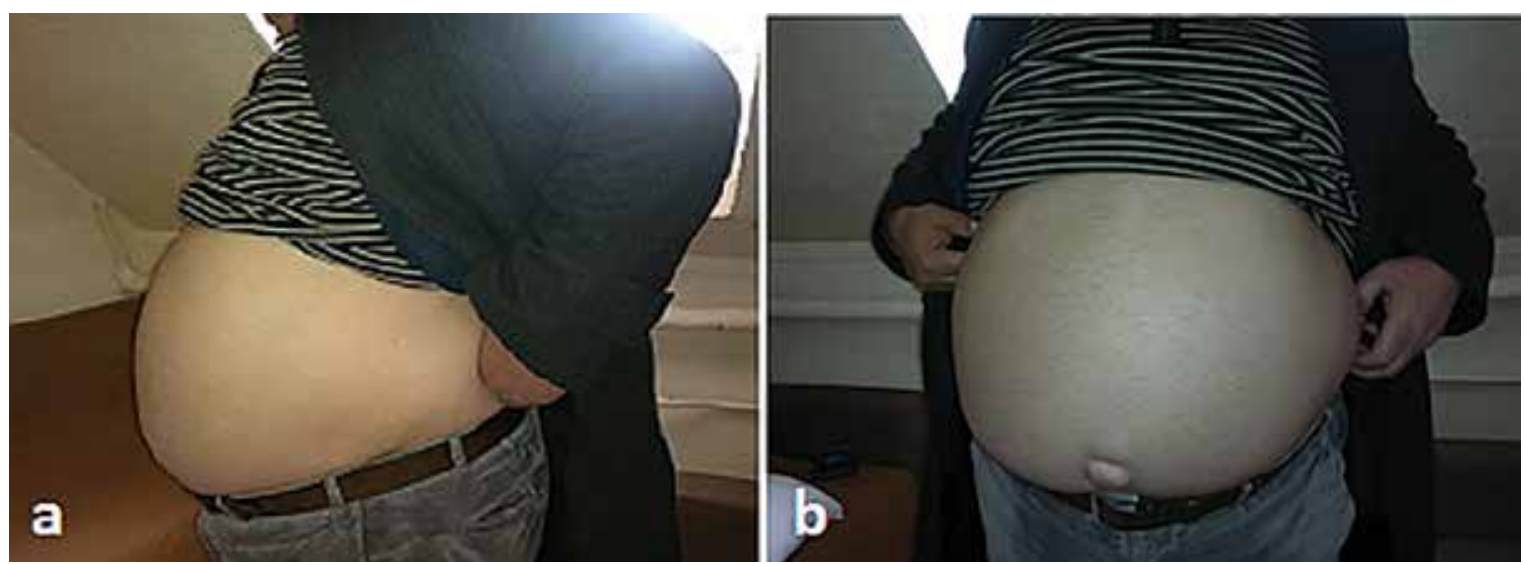

Resim 1a. Morbid obez olan hastanın görünümü.

Resim 1b. Operasyon öncesinde çekilen direkt üriner sistem grafisi'nde $3 \mathrm{~cm}$ çapındaki şüpheli radyoopasite (ok ile işaretli). 
TUNCEL VE ARK

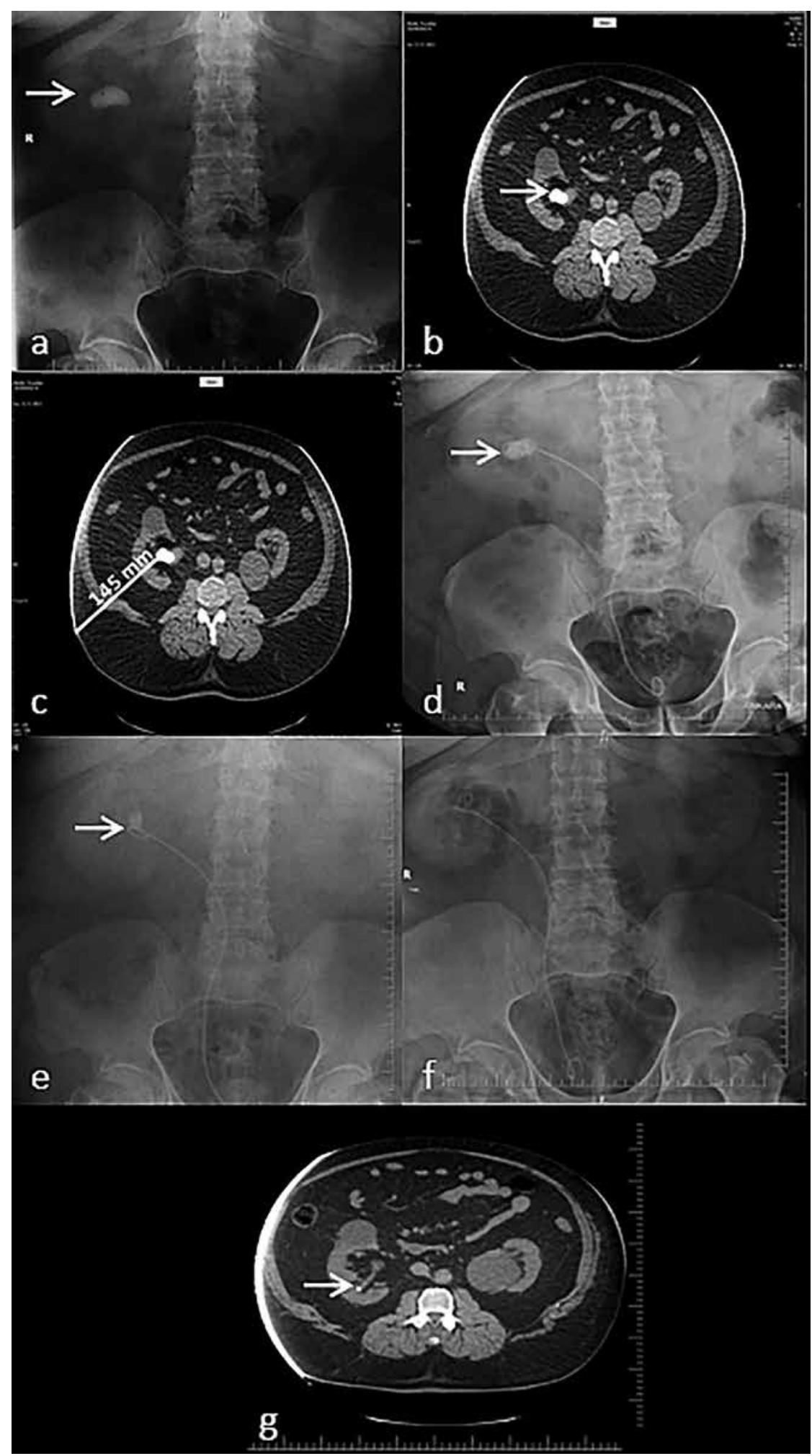

Resim 1c. Operasyon öncesinde çekilen tüm karın bilgisayarlı tomografisi'nde $3.2 \mathrm{~cm}$ çapındaki taş (ok ile işaretli). Resim 1d. Tüm karın bilgisayarlı tomografisi’nde cilt-böbrek taşı arasında ölçülen mesafe $(14.5 \mathrm{~cm})$.

Resim 1e. İlk operasyon sonrasında çekilen direkt üriner sistem grafisi'nde saptanan $2.3 \mathrm{~cm}$ çapındaki rezidüel taş (ok ile işaretli).

Resim 1f. İkinci operasyon sonrasında çekilen direkt üriner sistem grafisi'nde saptanan $1.3 \mathrm{~cm}$ çapındaki rezidüel taş (ok ile işaretli).

Resim 1g. Üçüncü operasyon sonrasında çekilen direkt üriner sistem grafisi.

Resim 1h. Üçüncü operasyon sonrasında çekilen tüm karın bilgisayarlı tomografisi'nde sağ böbrek alt polde saptanan 4 mm çapındaki klinik önemsiz rezidüel taş (ok ile işaretli) 
hipertansiyon ve sigara kullanımına bağlı olarak gelişen kronik tıkayıcı akciğer hastalığı tanıları nedeni ile medikal tedavi aldığı öğrenildi. Hastanın daha önceki dönemde herhangi bir cerrahi girişim öyküsü yok idi. Yapılan fizik muayenede, vücut ağırlığı $143 \mathrm{~kg}$, boy uzunluğu ise $170 \mathrm{~cm}$ olarak ölçüldü. Bu değerler ile vücut kitle indeksi (VKİ) $49.5 \mathrm{~kg} / \mathrm{m}^{2}$ olarak hesaplandı. VKİ'ne göre hastanın morbid obez kategorisinde olduğu tespit edildi (Resim 1a). Yapılan biyokimyasal laboratuvar incelemesinde, serum lipit değerlerinin yüksekliği dışında anormallik saptanmadı. Tam idrar tetkiki ve idrar kültürü sonuçları normal idi. Direkt üriner sistem grafisi'nde, sağ tarafta L2 vertebranın yaklaşık olarak üç $\mathrm{cm}$ lateralinde $3 \mathrm{~cm}$ çapında şüpheli radyoopasite mevcut idi (Resim 1b). Yapılan tüm karın kontrastlı bilgisayarlı tomografisi'nde ise sağ böbrek pelvis renalis lokalizasyonunda $3.2 \mathrm{~cm}$ çapında orta kaliks grubuna uzanan staghorn böbrek taşı saptand 1 (Resim 1c). Her iki böbrek fonksiyone idi. Bilgisayarlı tüm karın tomografisi'nde cilt-böbrek taşı arasındaki mesafe 14.5 cm olarak ölçüldü (Resim 1d). Tedavi için hospitalize edilen hastanın Anesteziyoloji ve Reanimasyon kliniği ile yapılan konsültasyon sonucunda anestezi alma açısından riski ASA 3 (Ciddi sistemik hastalığı olan hasta, günlük aktiviteleri etkilemeyen) olarak tarafımıza bildirildi.

Mevcut bulgular ışığında PNL ve açık cerrahi sırasında oluşabilecek cerrahi ve anestezi komplikasyonları ve tekrar girişim olasılığı göz önünde bulundurularak olgumuza RİRC yapılması kararlaştırıldı. Öncelikli olarak olgumuza yapılacak olan tedavi ve komplikasyonları ile tekrar girişim olasılığı hakkında bilgi verilerek yazılı onam formu ile yapılacak cerrahi işlem için onayı alındı.

\section{Cerrahi İşlem}

Operasyonun hemen öncesinde parenteral 3. kuşak sefalosporin profilaksisi sonrasında genel anestezi altında litotomi pozisyonunda uygun saha temizliği ve örtümü takiben 22 F rijit sistoskop (Karl Storz ${ }^{\mathrm{TM}}$, Almanya) ile girilerek sistoskopi yapıldı ve her iki üreter orifisi tanımlandı. Takiben hem üreterde dilatasyon sağlamak, hem de sağ üreterden böbreğe kılavuz tel yerleştirmek amacı ile $9 \mathrm{~F}$ semirijit üreteroskop (Karl Storz ${ }^{\mathrm{TM}}$, Almanya) ile sağ üreteropelvik bileşkeye kadar ilerlendi ve 0.035 inç çapında ve $150 \mathrm{~cm}$ uzunluğundaki kılavuz tel (Sensor $^{\mathrm{TM}}$, Boston Scientific, Amerika Birleşik Devletleri) sağ böbreğe skopi eşliğinde ilerletildi. Daha sonra $9.5 \mathrm{~F}$ çapında ve $45 \mathrm{~cm}$ uzunluğundaki üreter erişim kılıfı (Cook ${ }^{\mathrm{TM}}$, Cook, İrlanda) kılavuz tel üzerinden skopi eşliğinde sağ üreteropelvik bileşkenin $1 \mathrm{~cm}$ distaline kadar ilerlenerek yerleştirildi. Takiben, bükülebilir üreteroskop (FlexX2 ${ }^{\mathrm{TM}}$, Karl Storz, Almanya) ile üreter erişim kılıfından girilerek sağ böbrek pelvis renalis lokalizasyonundaki taş görülerek $30 \mathrm{~W}$ Holmium lazer cihazı (Sphinx $X^{\mathrm{TM}}$, Lisa, Almanya) kullanılarak 275 mikron çapındaki lazer probu ile kırıldı. Her işlem sonunda $4.8 \mathrm{~F}$ çapinda JJ stent skopi eşliğinde yerleştirildi.

Olgumuza 6 haftalık aralıklar ile toplam 3 kez RIRC uygulandı Operasyon süreleri sırası ile 50, 55 ve 45 dakika idi. Her işlem sonrasında JJ stent yerleştirildi. Hastanede kalış süresi sırası ile 2, 2 ve 1 gün idi. Her üç işlemde de; minör ve majör komplikasyon gelişmedi. İlk ve ikinci işlemde direkt üriner sistem grafisi'nde saptanan rezidüel taş boyutları sırası ile 2.3 ve $1.3 \mathrm{~cm}$ idi (Resim 1e ve f). Üçüncü işlem sonrasında direkt üriner sistem grafisi'nde rezidüel taş saptanmadı (Resim 1g). JJ stent 3 hafta sonra çıkarıldı. Takiben çekilen tüm karın bil- gisayarlı tomografisi'nde sağ böbrek alt polde bir adet $4 \mathrm{~mm}$ çapında klinik önemsiz rezidüel taş saptandı (Resim 1h). Bu taş için ek bir cerrahi girişim düşünülmedi.

Operasyon sonrasında elde edilen taşların analiz sonucu kalsiyum oksalat monohidrat olarak raporlanan hastaya medikal profilaksi amaci ile oral potasyum sitrat (Urocit-K ${ }^{\mathrm{TM}}$, Aymed Medikal, Türkiye) 40 mEq/gün tedavisi başlandı.

\section{Tartışma}

Obezite ile üriner sistem taş hastalığı oluşumu arasında kuvvetli bir ilişki olduğu çeşitli çalışmalarda ortaya konulmuştur $(3,15)$. Obez hastalarda üriner sistem taş hastalığının cerrahi tedavisinde çeşitli zorluklar bulunmaktadır. Çünkü bu hastalarda cerrahi sonrasında solunumsal, kardiyovasküler ve tromboembolik komplikasyonların görülme oranı obez olmayan hastalara göre daha fazladır $(13,16)$.

Obez hastalarda böbrek taşlarının cerrahi tedavisinde PNL, ilk sırada yer alan tedavi yöntemidir. Bagrodia ve ark.'larının VKİ'nin PNL sonuçları üzerine etkisini araştırdıkları çalışmasında, normal kilolu, şişman, obez ve morbid obez hastalar arasında taşsızlık oranı, komplikasyon oranı, operasyon süresi ve hastanede kalış süresi arasında fark olmadığ 1 rapor edilmiştir (17). Başka bir çalışmada, PNL yapılan obez ve obez olmayan hastalar arasında taşsızlık oranı, hemoglobin düşüşü, operasyon sonrasında analjezik kullanım miktarı, hastanede kalış süresi ve komplikasyon oranları arasında fark saptanmamıştır (18). Ancak uluslararası literatürde, obezitenin PNL'nin sonuçları üzerine olumsuz etki gösterdiğini bildiren çalışmalar da mevcuttur. Fuller ve ark.'larının VKİ'ne göre sınıflanan 3.709 hastadaki PNL sonuçlarını değerlendirdikleri çalışmasında, obez hastalarda düşük taşsızlık ve yüksek tekrar girişim oranı bildirilmiştir (5). Faerber ve ark.'ları ise; obez ve obez olmayan hastalarda PNL sonrasındaki komplikasyon oranlarını sırası ile \%37 ve \%17 olarak rapor etmişlerdir (19).

Obezite, böbrek taşlarında vücut dişı şok dalgası ile taş kırma sonuçlarını olumsuz yönde etkilemektedir. Pareek ve ark.'ları; obez hastalarda, obez olmayan hastalara göre vücut dışı şok dalgası ile böbrek taşı kırma sonrasında daha fazla oranda rezidüel taş saptadıklarını bildirmiştir (20). Özellikle böbrek taşının lokalize edilerek kırılmasındaki zorluk ve ciltböbrek taşı arasındaki mesafenin fazla olması nedeni ile şok dalgasının etkinliğinin azalması gibi nedenler obez hastalarda bu yöntemin başarısını sınırlamaktadır $(5,8)$.

Bükülebilir üreteroskop ve lazer taş kırma cihazlarındaki teknolojik gelişmelere paralel olarak RIRC'nin böbrek taşlarının cerrahi tedavisinde uygulama sıklığı artmıştır. Deneyimin artması ile birlikte uluslararası literatürde, RİRC uygulanan hastalarda yüksek taşsızlık oranları bildirilmeye başlanmıştır. Bu oranlar, yüksek taş yüküne sahip hastalarda bile PNL uygulanan hasta serileri ile karşılaştırılabilir hale gelmiştir $(21,22)$. Uluslararası literatürde yer alan çeşitli çalışmalarda, RIRC üreter ve böbrek taşlarının cerrahi tedavisinde ilk basamak tedavi yöntemi olarak önerilmektedir. Best ve Nakada'nın çalışmasında, obez ve obez olmayan hastalarda proksimal üreter taşlarının tedavisinde RİRC sonrasında taşsızlık oranları sırası ile \%91 ve \%81 olarak rapor edilmiştir (12). Bu çalışmanın yazarları, RİRC'nin obez hastalarda düşük komplikasyon oranı ve kısa operasyon süresi ile yap1labileceğini bildirmiştir. Obez hastalarda üreter ve böbrek taşlarının cerrahi tedavisi için uygulanan RİRC sonuçlarını 
7 tane uluslararası çalışmayı temel alarak değerlendiren bir meta-analizde ise taşsızlık oranı genel olarak \%87.5 olarak bildirilmiştir (13). Alt grup analizinde ise $2 \mathrm{~cm}$ 'nin altındaki böbrek taşlarında taşsızlık oranı \%84.6 olarak rapor edilmiştir. Bu meta-analizde, genel komplikasyon oran1 \%11 olarak rapor edilmiş ve hiçbir hastada majör komplikasyon saptanmadığ mada, 2 cm'den küçük böbrek taşı nedeni ile RİRC yapılan normal kilolu, şişman ve obez hastaların değerlendirildiği bir çalışmada ise gruplar arasında taşsızlık oranları benzer bulunmuştur (\%85.2, \%84.4 ve \%81.6) (14). Bu çalışmanın yazarları, gruplar arasında operasyon süresi, komplikasyon oranı ve hastanede kalış süresi açısından farklılık olmadığını bildirmiştir.

Bazı çalışmalar, yüksek taş yüküne sahip obez hastalarda uzun operasyon süresi, ek girişim gerekliliği ve anesteziye bağlı olarak gelişen yüksek komplikasyon oranları nedeni ile RİRC yapılmasını desteklememektedir $(1,15)$. Ancak RİRC'de hastaya supin pozisyon verilmesi nedeni ile solunumsal ve anesteziye bağlı komplikasyonlara daha az rastlandığı genel kabul gören bir düşüncedir (14).

Bizim olgumuzda; kronik tıkayıcı akciğer hastalığı öyküsünün bulunması, VKİ'nin $49.5 \mathrm{~kg} / \mathrm{m}^{2}$ olması (morbid obez) ve tüm karın bilgisayarlı tomografisi ile ölçülen cilt-böbrek taşı arasındaki mesafenin $14.5 \mathrm{~cm}$ olması nedeni ile sağ böbrekteki yüksek taş yüküne rağmen PNL ve açık cerrahi sırasında oluşabilecek cerrahi ve anestezi komplikasyonları göz önünde bulundurularak RİRC yapılması kararlaştırıldı. Olgumuza, cerrahi öncesinde tekrar girişime gerek duyulması olasılığı hakkında bilgi verildi. Olgumuza, 6 haftalık aralıklar ile toplam 3 seans RİRC yapılarak taşsızlık sağlandı.

\section{Sonuç}

RİRC, 2 cm'nin üzerinde böbrek taşına sahip morbid obez hastalarda tekrarlayan girişim olasılığı hakkında hastaya bilgi verilerek deneyimli merkezlerde yüksek taşsızlık ve düşük komplikasyon oranları ile uygulanabilecek bir tedavi yöntemidir.

\section{Kaynaklar}

1. CalvertRC, Burgess NA.Urolithiasis and obesity:metabolic and technical considerations. Curr Opin Urol 15: 113-117, 2005.

2. Asplin JR. Obesity and urolithiasis. Adv Chronic Kidney Dis 16: 11-20, 2009.

3. Curhan GC. Epidemiology of stone disease. Urol Clin North Am 34: 287-293, 2007.

4. Ekeruo WO, Tan YH, Young MD, Dahm P, Maloney ME, Mathias BJ, et al. Metabolic risk factors and impact of medical therapy on the management of nephrolithiasis in obese patients. J Urol 172: 159-163, 2004.

5. Fuller A, Razvi H, Denstedt JD, Nott L, Pearle M, Cauda $\mathrm{F}$, et al. The CROES percutaneous nephrolithotomy global study:the influence of body mass index on outcome. J Urol 188: 138-144, 2012.

6. Olbert PJ, Hegele A, Schrader AJ, Scherag A, Hofmann R. Pre and perioperative predictors of short-term clinical outcomes in patients undergoing percutaneous nephrolitholapaxy. Urol Res 35: 225-230, 2007.

7. Tefekli A, Kurtoglu H, Tepeler A, Karadag MA,
Kandirali E, Sari E, et al. Does the metabolic syndrome or its components affect the outcome of percutaneous nephrolithotomy? J Endourol 22: 35-40, 2008.

8. Thomas R, Cass AS. Extracorporeal shock wave lithotripsy in morbidly obese patients. J Urol 150: 30-32, 1993.

9. Breda A, Ogunyemi O, Leppert JT, Schulam PG. Flexible ureteroscopy and laser lithotripsy for multiple unilateral stones. Eur Urol 55: 1190-1196, 2009.

10. Wiesenthal JD, Ghiculete D, D'A Honey RJ, Pace KT. A comparison of treatment modalities for renal calculi between 100 and $300 \mathrm{~mm} 2$ : are shockwave lithotripsy, ureteroscopy, and percutaneous nephrolithotomy equivalent? J Endourol 25: 481-485, 2011.

11. Bozkurt OF, Resorlu B, Yildiz Y, Can CE, Unsal A. Retrograde intrarenal surgery versus percutaneous nephrolithotomy in the management of lower-pole renal stones with a diameter of 15 to $20 \mathrm{~mm}$. J Endourol 25: 1131-1135, 2011.

12. Best SL, Nakada SY. Flexible ureteroscopy is effective for proximal ureteral stones in both obese and nonobese patients:a two year, single-surgeon experience. Urology 77: 36-39, 2011.

13. Aboumarzouk OM, Somani B, Monga M. Safety and efficacy of ureteroscopic lithotripsy for stone disease in obese patients:a systematic review of the literature. BJU Int 110 (8 Pt B): E374-E380, 2012.

14. Caskurlu T, Atis G, Arikan O, Pelit ES, Kilic M, Gurbuz C. The impact of body mass index on the outcomes of retrograde intrarenal surgery. Urology 81: 517-521, 2013.

15. Tomaszewski JJ, Smaldone MC, Schuster T, Jackman SV, Averch TD. Outcomes of percutaneous nephrolithotomy stratified by body mass index. J Endourol 24: 547-550, 2010.

16. Choban PS, Flancbaum L. Impact of obesity on surgical outcomes:a review. J Am Coll Surg 185: 593-603, 1997.

17. Bagrodia A, Gupta A, Raman JD, Bensalah K, Pearle MS, Lotan Y. Impact of body mass index on cost and clinical outcomes after percutaneous nephrostolithotomy. Urology 72: 756-760, 2008.

18. Koo BC, Burtt G, Burgess NA. Percutaneous stone surgery in the obese:outcome stratified according to body mass index. BJU Int 93: 1296-1299, 2004.

19. Faerber GJ, Goh M. Percutaneous nephrolithotripsy in the morbidity obese patient. Tech Urol 3: 89-95, 1997.

20. Pareek G, Hedican SP, Lee J, Nakada SY. Shock wave lithotripsy success determined by skin-tostone distance on computed tomography. Urology 66: 941-944, 2005.

21. Riley JM, Stearman L, Troxel S. Retrograde ureteroscopy for renal stones larger than $2.5 \mathrm{~cm}$. J Endourol 23: 13951398, 2009.

22. Hyams ES, Munver R, Bird VG, Uberoi J, Shah O. Flexible ureterorenoscopy and holmium laser lithotripsy for the management of renal stone burdens that measure 2 to 3 $\mathrm{cm}$ : a multi-institutional experience. J Endourol 24: 15831588, 2010.

Yazışma Adresi:

Altuğ Tuncel

Să̆lık Bakanlı̆̆ı, Ankara Numune Ĕ̆itim ve Araştırma Hastanesi,

3. Üroloji Kliniğii, 06120, Sihhiye, Ankara

Tel: +90 5553313393

Fax: +903123103460

e-mail: tuncelaltug@yahoo.com 